ORIGINAL ARTICLE

\title{
Consumerism in healthcare can be detrimental to child health: lessons from children with functional abdominal pain
}

\author{
K J Lindley, D Glaser, P J Milla
}

See end of article for

authors' affiliations

Arch Dis Child 2005;90:335-337. doi: 10.1136/adc.2003.032524

Correspondence to: Dr K J Lindley, Department of Gastroenterology, Institute of Child Health and Great Ormond Street Hospital for Children NHS Trust, Great Ormond Street, London WCIN 1EH, UK; k.lindley@ich. ucl.ac.uk

Accepted 3 March 2004

\begin{abstract}
Aims: To determine prognostic indicators in children with severe functional abdominal pain (FAP) and to test the hypothesis that "healthcare consumerism" in these families might be deleterious to the child. Methods: Retrospective analysis of a cohort of 23 children aged $<16$ years fulfilling the Rome II diagnostic criteria for FAP during the period December 1997 to February 2001. Poor outcome was defined as continued pain and failure to return to normal functioning $>12$ months after onset.

Results: Poor outcome was associated with refusal to engage with psychological services, involvement of more than three consultants, lodging of a manipulative complaint with hospital management by the child's family, and lack of development of insight into psychosocial influences on symptoms. Three of four adverse prognostic indicators reflected healthcare consumerism by the families.

Conclusions: Actions of families who lack insight into their child's illness may perpetuate FAP in childhood. A culture of parental consumerism in healthcare, however well intentioned, needs to be accompanied by robust systems to protect the interests of the child.
\end{abstract}

$\mathrm{F}$ unctional abdominal pain (FAP) in childhood is defined by international consensus (Rome II criteria). ${ }^{1}$ In essence the child/adolescent must have had at least 12 weeks of abdominal pain which is unrelated to physiological events, associated with some loss of daily functioning, and having no other explanation. The consensus acknowledges that unrecognised psychological factors are commonly at least partially responsible for the disability associated with the condition and that parent-child enmeshment is not uncommon. ${ }^{1}$

A biopsychosocial model whereby interactions between psychosocial factors and altered physiology via the brain-gut axis resulting in functional GI symptoms is widely accepted (fig 1). ${ }^{2-4}$ Stress is a common precipitant and symptoms are commonly perpetuated by the illness behaviour of the individual and his/her family. ${ }^{5}$ The enteric mast cell-nerve connection is well validated and explains one facet of the propensity of this group to develop visceral hypersensitivity. ${ }^{4}$ Evidence of activation of this pathway in this group of children is provided in an associated manuscript (Schäppi et al, submitted).

Parents of children with FAP not uncommonly show symptoms of anger and hostility towards the medical profession, ${ }^{8}$ and may be reluctant to accept medical reassurance, bringing them further into conflict with the profession. ${ }^{9}$ Modernisation of the National Health Service (NHS) in the UK includes initiatives which make the health service more responsive to the patient's needs and wants. It is assumed that what a patient ("consumer") wants is in their best interests. In paediatrics it is the consumer's representative (parent or advocate) who is empowered to act on behalf of the child-actions which might benefit or compromise the child's health. The "new NHS" provides parents with scope to challenge healthcare providers, either via the patient advocate and liaison service (PALS) or the formal NHS complaints system, when there are differences between what they want and what the physician perceives as best for the patient. While this is usually to the patient's advantage, this is not guaranteed.

We hypothesised that "healthcare consumerism" in families who lack insight into their child's problem might be deleterious for the child with FAP.

\section{METHODS}

Twenty three consecutive referrals with FAP to a single tertiary paediatric gastroenterologist during the period December 1997 to February 2001 were studied retrospectively. For inclusion the children had to fulfil the Rome II criteria for paediatric $\mathrm{FAP}^{1}$ and had to have evidence of visceral hypersensitivity ${ }^{10}$ on abdominal examination. All 23 were investigated according to in-house clinical service guidelines for the investigation of abdominal pain. All underwent measurement of inflammatory markers, urine microscopy and culture, and abdominal ultrasonography. In addition they had all undergone upper and lower GI endoscopy, including ileoscopy with mucosal biopsy. Other investigations had been performed as clinically indicated. Where FAP was positively diagnosed, concurrent psychological referral was advocated.

Poor outcome was defined as persistence of pain and failure to return to normal levels of functioning within 12 months of the onset of symptoms. Predictors of outcome were analysed using Fisher's exact test.

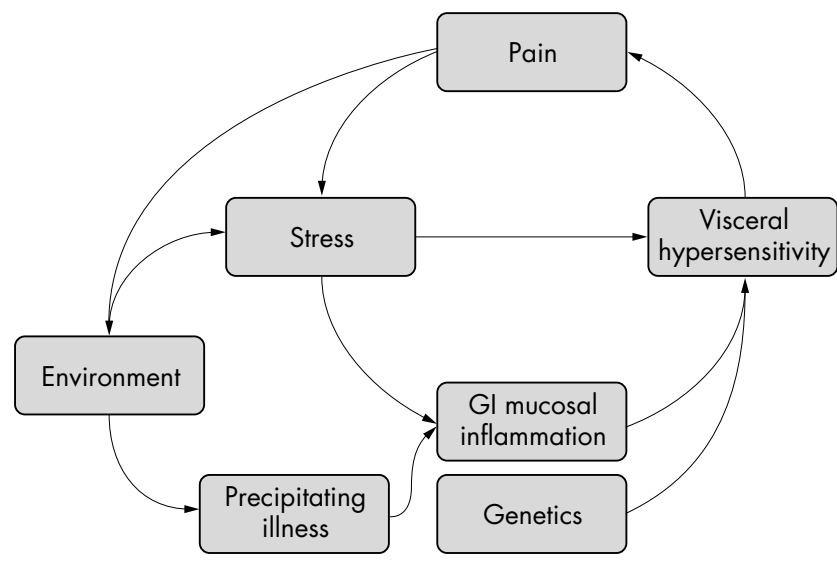

Figure 1 Biopsychosocial model of functional gastrointestinal disease in which genetics, environment (physical and psychosocial), and the nervous system (central and enteric) interact to cause symptoms. 


\section{RESULTS}

The 23 children included 11 males and 12 females, median age 14 years (range $8-15$ years) (table 1 ).

At the time of referral all children were under the care of a consultant paediatrician $(\mathrm{n}=19)$ or consultant surgeon $(n=4)$. Fifteen had seen more than two consultants, and four had already seen a tertiary referral hospital paediatric gastroenterologist (table 1). Of the 15 children who had already seen two or more consultants, the further referral was at the parents' request in 14, and instigated with GP referral without prior knowledge of the responsible consultant in 13. Sixteen sought "emergency" referral, although only one referring doctor felt this was appropriate. Many families had lost empathy with the medical profession, and nine were aggressive or confrontational at first consultation, perhaps reflecting the high levels of conflict within the families themselves.

While children were investigated according to in-house clinical service guidelines and investigative algorithms, seven parents were at some stage unhappy with the physician's choice of investigative procedure and requested other specific investigations. Two families achieved these through referral elsewhere. In neither instance did the results influence diagnosis or management.

Mucosal biopsy of the gastrointestinal tract was frequently abnormal, as is established in functional gastrointestinal disease in adulthood. ${ }^{11}{ }^{12}$ These findings in this group of children are presented in an associated manuscript (Schäppi et al, submitted).

Only 13 families accepted psychological referral. Evidence of significant family conflict/dysfunction and poor insight into the counterproductive consequences of parental attitude/ behaviour on the pattern of illness was found in 12. Eleven of 13 improved and returned to normal functioning within 12 months (median 7 months). All 11 subsequently acknowledged the role of psychological factors in the genesis/ maintenance of symptoms.
Ten refused psychological referral; three improved, two were referred (without reference to the consultant) elsewhere, and in five no improvement was seen 12 months or more after initial consultation. Families of all three who improved developed insight into the role of psychological factors in the genesis of symptoms.

Twelve families complained about some aspect of their care in writing (three at other hospitals and nine at Great Ormond Street Hospital-by letter to consultant $(n=3)$, via formal complaints system $(n=8)$, and via an $\mathrm{MP}(\mathrm{n}=1))$. Four complaints related to consultant availability (length of wait for outpatient appointment, duration of consultation, access to consultant between hospital attendances). Eight complaints could be construed to be overt attempts to manipulate some facet of their child's care (for example, further inappropriate referral or investigation)-hereafter termed a "manipulative complaint". Investigation of the six official "in-house" complaints found no evidence of poor clinical performance.

Age, sex, severity of initial symptoms, parental aggression/ hostility, or use of the hospital complaints system (all complaints) were not associated with outcome. Neither was intestinal mucosal histological change associated with outcome. Poor outcome (continued pain and failure to return to normal functioning $>12$ months after onset) was associated with: lack of development of insight into psychosocial influences on symptoms $(\mathrm{p}<0.001$, relative risk 7.49 , 95\% CI 1.14 to 49.56$)$, refusal to engage with psychological services $(p<0.05$, relative risk $4.55,95 \%$ CI 1.19 to 17.35$)$, involvement of more than three consultants $(\mathrm{p}<0.001$, relative risk $7.00,95 \%$ CI 1.94 to 25.26 ), and lodging of a manipulative complaint $(\mathrm{p}<0.05$, relative risk $3.25,95 \%$ CI 1.11 to 9.48$)$.

\section{DISCUSSION}

Current models of functional gastrointestinal disease recognise the links between environment, genetics, and stress

Table 1 Features of 23 children with functional abdominal pain

\begin{tabular}{|c|c|c|c|c|c|c|c|c|c|c|c|c|}
\hline Age & Sex & Abd pain & $\begin{array}{l}\text { School } \\
\text { avoidance }\end{array}$ & $\begin{array}{l}\text { Parent } \\
\text { hostility }\end{array}$ & Psych & $\begin{array}{l}\text { Psych } \\
\text { disorder }\end{array}$ & Outcome & Insight & Complaint & $\begin{array}{l}\text { Manip } \\
\text { complaint }\end{array}$ & Consultants & $\begin{array}{l}\text { Parenta } \\
\text { D/S }\end{array}$ \\
\hline 12 & $\mathrm{~F}$ & ++++ & ++ & + & $Y$ & +++ & 1 & $Y$ & + & + & 6 & \\
\hline 15 & $M$ & ++++ & ++ & + & $Y$ & + & L & $?$ & - & & 3 & $Y$ \\
\hline 10 & $\mathrm{~F}$ & +++ & ++ & - & $Y$ & ++ & 1 & $Y$ & - & & 2 & \\
\hline 13 & $M$ & ++ & $+1-$ & ++ & $Y$ & + & i & $Y$ & + & & 2 & \\
\hline 14 & $M$ & ++ & ++ & + & $Y$ & + & I & $\mathrm{N}$ & + & & 3 & \\
\hline 11 & $\mathrm{~F}$ & +++ & ++ & +++ & $Y$ & ++ & 1 & $N$ & + & & 1 & \\
\hline 15 & $M$ & ++ & ++ & +++ & $\mathrm{N}$ & $?$ & $N B / L$ & $\mathrm{~N}$ & + & + & 7 & \\
\hline 12 & $\mathrm{~F}$ & + & + & +++ & $N$ & + & 1 & $Y$ & - & & 1 & \\
\hline 14 & $\mathrm{~F}$ & +++ & + & +++ & $Y$ & ++ & I & $Y$ & + & + & 2 & $Y$ \\
\hline 15 & $M$ & ++ & + & - & $N$ & $?$ & I & $Y$ & - & & 1 & \\
\hline 13 & $\mathrm{~F}$ & + & - & + & $N$ & $?$ & L & $?$ & + & & 2 & \\
\hline 14 & $\mathrm{~F}$ & ++ & +++ & ++ & $N$ & $?$ & NB & $N$ & + & + & 4 & $Y$ \\
\hline 12 & $M$ & ++ & +++ & - & $Y$ & ++ & I & $Y$ & - & & 2 & Y \\
\hline 13 & $M$ & +++ & + & & $\mathrm{N}$ & $?$ & 1 & $N$ & - & & 1 & \\
\hline 14 & $M$ & ++++ & ++++ & +++ & $N$ & +++ & NB & $N$ & + & + & 6 & \\
\hline 14 & $M$ & + & + & - & $Y$ & - & I & $Y$ & - & & 2 & \\
\hline 13 & $\mathrm{~F}$ & +++ & ++++ & - & $Y$ & ++ & NB & $\mathrm{N}$ & - & & 4 & $Y$ \\
\hline 15 & $\mathrm{~F}$ & ++++ & ++++ & + & $Y$ & +++ & NB & $N$ & + & + & 7 & $Y$ \\
\hline 14 & $\mathrm{~F}$ & +++ & ++ & +++ & $\mathrm{N}$ & $?$ & NB & $N$ & + & + & 2 & $Y$ \\
\hline 12 & $\mathrm{~F}$ & ++++ & +++ & + & $Y$ & + & NB & $N$ & - & & 2 & $Y$ \\
\hline 10 & $M$ & ++++ & +++ & ++ & $N$ & $?$ & NB & $N$ & + & + & 4 & \\
\hline 14 & $M$ & ++ & ++ & - & $Y$ & + & 1 & $Y$ & - & & 3 & \\
\hline 15 & $\mathrm{~F}$ & +++ & +++ & - & $\mathrm{N}$ & $?$ & NB & $\mathrm{N}$ & - & - & 4 & \\
\hline
\end{tabular}

Severity of abdominal pain graded + to ++++

School avoidance graded + (missing $\geqslant 1 / 2$ day per week) to ++++ (no attendance for $>3$ months).

Parental hostility graded + to +++.

Psych, agreed to psychological referral.

Psychological disorder graded + to +++

Outcome: I, improved; NB, no better; L, lost to follow up.

Parental D/S: parental separation/divorce within two years of illness onset. 
(physical and psychosocial) in the disorder. ${ }^{15613}$ Psychosocial factors are not a cause but can affect the illness experience and clinical outcome. ${ }^{14}$ The families of this cohort of children with FAP were very "stressful" — characterised by high levels of confrontation and psychological dysfunction, as is the case with adult functional gastrointestinal disorders. ${ }^{15}$ Many parents had separated or divorced within a two year period of the onset of the FAP. Confrontation within these families frequently spilled over into the healthcare services, sometimes manifest as parental hostility towards medical staff or the submission of a written complaint about their child's medical care. The high prevalence of family conflict/ dysfunction and poor insight into the effects of this on the child in the 12/13 families who agreed to psychological assessment illustrates the many difficulties the clinician faces in managing these children and families.

It is the lack of insight of the family into the origins of the illness which underlie one of the greatest management difficulties. The severity of the symptoms are frequently such that there is a reluctance to accept the positive diagnosis of FAP; rather there is a drive to continue searching for an elusive physical cause by seeking multiple referrals and further investigations. The differences in illness perception of functional gastrointestinal disorders by patients and their medical carers is well recognised. ${ }^{16}$ In this instance the attitudes of the families of the patient appear to exaggerate such differences. Yielding to parental requests for multiple referrals risks inadvertent collusion and perpetuation of the illness. The clinician, acting in the best interests of the child, is frequently brought into conflict with parents and, when complaints are made, with hospital managers and other agencies who inadvertently collude to perpetuate the child's illness. ${ }^{17}$ Abuse or misuse of hospital complaints systems by parents lacking insight to subvert proper referral patterns, dictate clinical management, and avoid psychological referral may be to the detriment of their child. ${ }^{18}$ The stakes are high as inappropriate treatment risks lifelong health problems. ${ }^{19}$

Child protection legislation in the UK (Children Act 1989 England) uses the concept of significant harm as a threshold to justify compulsory intervention in family life in the best interests of the child. The actions of the families who lodged manipulative complaints or who refused to engage with psychological services may, in our view, sometimes approach this threshold.

Many factors may contribute to the family's relentless search for an illusive physical cause for their child's pain in preference to accepting a multidisciplinary approach to their child's symptoms. The clinician is usually best placed to determine whether such prejudices are unfounded rather than hospital managers investigating a complaint about the clinicians choice of treatment. ${ }^{20}$ Strict adherence to appropriate clinical service guidelines (as for example with adult irritable bowel syndrome ${ }^{21}$ ) in such circumstances will protect both the child and his/her physician.

There is a view that it is unnecessary to investigate children with symptomatology of this type at all. The severity and chronicity of symptoms are usually such that parents expect a physical diagnosis. In such circumstances a positive diagnosis of FAP is necessary to curtail the quest for a physical causeespecially as effective treatments are rarely speedy. The finding of mucosal eosinophilia, which was common in this cohort of children, empowers the physician considerably in making a firm diagnosis. Use of such evidence to invoke and explain the biopsychosocial model (fig 1) is important both in developing parental insight into the child's condition and in engendering an empathic relationship with those treating the child. Such a non-confrontational relationship between healthcare provider and patient/family is of established value in functional gastrointestinal disorders ${ }^{16}$ but is difficult to achieve when levels of confrontation are so high within the family. When insight is achieved consumerism matters not.

This study of children with FAP illustrates the dangers of "healthcare consumerism" in families who lack insight into the origins of their child's symptoms and how this can lead to an abuse of hospital complaints procedures which risks compromising the child's physical wellbeing. Consumerism within these families was detrimental to their child's health as measured by outcome at 12 months. Robust systems are needed to protect the child, and perhaps his/her physician from the effects of healthcare consumerism.

\section{Authors' affiliations}

K J Lindley, Department of Gastroenterology, Institute of Child Health and Great Ormond Street Hospital for Children NHS Trust, London, UK D Glaser, Department of Psychological Medicine, Institute of Child Health and Great Ormond Street Hospital for Children NHS Trust, London, UK

P J Milla, Department of Gastroenterology, Institute of Child Health and Great Ormond Street Hospital for Children NHS Trust, London, UK

Funding: Research at the Institute of Child Health and Great Ormond Street Hospital for Children NHS Trust benefits from R\&D funding received from the NHS Executive

Competing interests: none declared

\section{REFERENCES}

1 Rasquin-Weber A, Hyman PE, Cucchiara S, et al. Childhood functional gastrointestinal disorders. Gut 1999;45(suppl 2):I160-8.

2 Apley J, Naish N. Recurrent abdominal pain: a field survey of 1000 school children. Arch Dis Child 1958;33:165-70.

3 Drossman DA. The functional gastrointestinal disorders and the Rome II process. Gut 1999;45(suppl 2):111-5.

4 Ringel Y, Drossman DA. Irritable bowel syndrome: classification and conceptualization. J Clin Gastroenterol 2002;35:S7-10.

5 Creed F, Craig T, Farmer R. Functional abdominal pain, psychiatric illness, and life events. Gut 1988;29:235-42.

6 Drossman DA, Creed FH, Olden KW, et al. Psychosocial aspects of the functional gastrointestinal disorders. Gut 1999;45(suppl 2):1125-30.

7 van Ginkel R, Voskuiil WP, Benninga MA, et al. Alterations in rectal sensitivity and motility in childhood irritable bowel syndrome. Gastroenterology $2001 ; 120: 31-8$.

8 Liakopoulou-Kairis M, Alifieraki T, Protagora D, et al. Recurrent abdominal pain and headache-psychopathology, life events and family functioning. Eur Child Adolesc Psychiatry 2002;11:115-22.

9 Gulhati A, Minty B. Parental health attitudes, illnesses and supports and the referral of children to medical specialists. Child Care Health Dev 1998;24:295-313.

10 Trimble KC, Farouk R, Pryde A, et al. Heightened visceral sensation in functional gastrointestinal disease is not site-specific. Evidence for a generalized disorder of gut sensitivity. Dig Dis Sci 1995;40:1607-13.

11 Gwee KA, Collins SM, Read NW, et al. Increased rectal mucosal expression of interleukin 1 beta in recently acquired post-infectious irritable bowel syndrome. Gut 2003;52:523-6.

12 Milla PJ. Irritable bowel syndrome in childhood. Gastroenterology 2001;120:287-90.

13 Alfven G. One hundred cases of recurrent abdominal pain in children: diagnostic procedures and criteria for a psychosomatic diagnosis. Acto Paediatr 2003;92:43-9.

14 Dalton CB, Drossman DA. Diagnosis and treatment of irritable bowel syndrome. Drugs Today (Barc) 1998;34:585-92.

15 Bennett EJ, Piesse C, Palmer K, et al. Functional gastrointestinal disorders: psychological, social, and somatic features. Gut 1998;42:414-20.

16 Dalton CB, Drossman DA, Hathaway JM, et al. Perceptions of physicians and patients with organic and functional gastrointestinal diagnoses. Clin Gastroenterol Hepatol 2004;2:121-6

17 Hey E, Fleming P, Sibert J. Learning from the sad, sorry saga at Stoke. Arch Dis Child 2002;86:1-3.

18 Rowland M, Crushell E, Gormally SM, et al. Prognostic factors in severe recurrent abdominal pain-are there any? Gut 2001 ;(suppl III):2589.

19 Campo JV, Di Lorenzo C, Chiappetta L, et al. Adult outcomes of pediatric recurrent abdominal pain: do they just grow out of it? Pediatrics 2001;108:e1.

20 Creed F, Fernandes L, Guthrie E, et al. The cost-effectiveness of psychotherapy and paroxetine for severe irritable bowel syndrome. Gastroenterology 2003; 124:303-17.

21 Jones J, Boorman J, Cann P, et al. British Society of Gastroenterology guidelines for the management of the irritable bowel syndrome. Gut 2000;47(suppl 2):ii 1-19. 